\title{
A Simplified Approach for Predicting Temperature Profile in Steel Members With Locally Damaged Fire Protection
}

\author{
M. M. S. Dwaikat, Industrial Design Faculty, Delft Technical University, \\ Delft, The Netherlands \\ V. K. R. Kodur*, Department of Civil and Environmental Engineering, \\ Michigan State University, East Lansing, MI, USA
}

Received: 2 September 2010/Accepted: 8 September 2011/Published online: 22 September 2011

\begin{abstract}
Steel structures in building are to be provided with external insulation to delay temperature rise and associated strength degradation when exposed to fire. However, due to delicateness and fragility of some insulation systems, damage might occur in these insulation systems during their service life, and such damage can lead to rapid rise in steel temperature and result in lower fire resistance of structural members. Currently, there are no simple calculation methods for quantifying the effect of insulation loss on steel temperature. In this paper, a simple approach is proposed for tracing the temperature profile in steel members with partial loss of fire protection. The method is developed based on modifying the existing one-dimensional finite difference solutions of the heat transfer equation. The validity of the proposed method is established by comparing the predictions from the proposed method against temperatures obtained from finite element heat transfer model that is created using ANSYS. The comparisons indicate that the proposed method is capable of predicting temperature in steel members with partially damaged insulation to a good degree of accuracy over a wide range of situations. Further, the simplicity of the proposed method makes it attractive for use in fire resistance assessment in steel structures.
\end{abstract}

Keywords: Heat transfer, Fire protection, Insulation loss, Radiation, Convection, Fire resistance

\section{Abbreviations}

$\begin{array}{ll}A_{p} & \text { Insulation cross sectional area } \\ F_{p} & \text { The heated perimeter of the cross section } \\ F_{y} & \text { Yield strength of steel at room temperature } \\ h_{c} & \text { The convective heat transfer coefficient } \\ H_{p} & \text { The heat stored in the insulation } \\ H_{s} & \text { The heat stored in the steel } \\ k & \text { Thermal conductivity } \\ k_{p} & \text { The thermal conductivity of the insulation material } \\ \ell_{p} & \text { Equivalent length of the lost insulation area } \\ m & \text { Interpolation coefficient for averaging temperature in insulation using fire } \\ n_{y}, n_{z} & \text { temperature and steel temperature }\end{array}$

\footnotetext{
* Correspondence should be addressed to: V. K. R. Kodur, E-mail: kodur@egr.msu.edu
} 


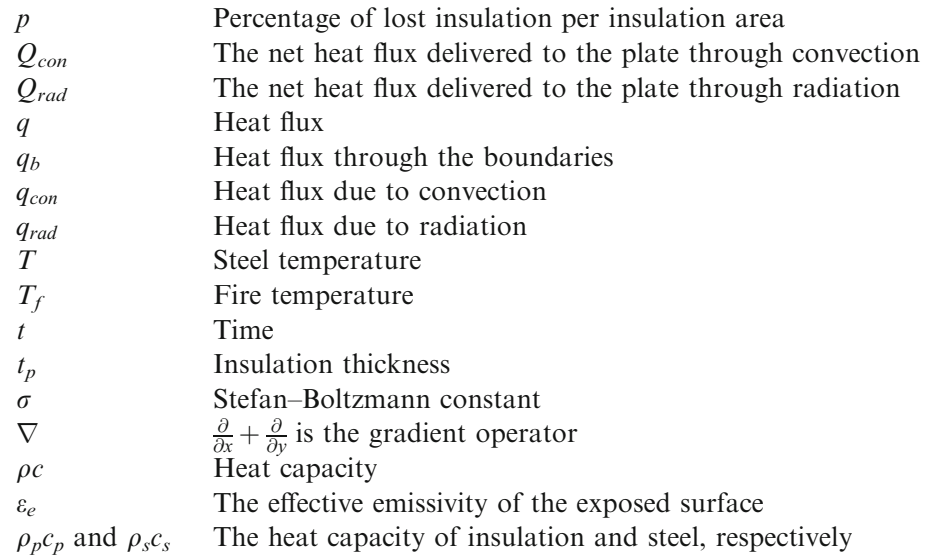

\section{Infroduction}

Damage to fire insulation on steel structural members can occur due to many reasons, including accidental peeling of the material, bond degradation due to environmental factors, or fall off due to sudden impact load. Loss of insulation can lead to a rapid rise in steel temperature in the event of fire and this can cause drastic reduction in strength and stiffness of steel, and hence the member carrying capacity. Also, uneven loss of insulation on one side of the protected section can lead to significant thermal gradients to develop along the cross section, and this thermal gradient can generate lateral deflection (thermal bowing) or bending moments due to restraint effects.

Up to date, there is a lack of simple methods for assessing the fire resistance of steel members with partial loss of insulation. Currently, the only method for such analysis is using complex finite element models that require skilled expertise and a large amount of input parameters. Recently, few studies have been carried out to investigate the effect of partial loss of insulation (especially spray-applied fire resistance materials "SFRM") on fire resistance of steel structures. In most of these studies, the insulation damage was simulated by removing a certain amount of insulation from the face of the member/section. While there is a lack of experimental studies on the effect of partial loss of fire protection on fire response, there are quite a few numerical studies on this issue. Tomecek and Milke [1] and Ryder et al. [2] performed a 2D and 3D finite element analysis on a steel column with partial loss of insulation, respectively. These studies concluded that a $4 \%$ loss of insulation per surface area resulted in a $15 \%$ reduction in fire resistance of a $1 \mathrm{~h}$ fire rated W10 $\times 49$ column and a $40 \%$ reduction in fire resistance for a 2 -h fire rated column.

Fontana and Knobloch [3] and Milke et al. [4] conducted a nonlinear 3D finite element analysis to analyze steel columns with partial insulation loss. They concluded that that extent of insulation damage and the size of the column have significant influence on the thermal response of a column regardless of insulation thickness. 
The effect of partial loss of SFRM fire protection on the load carrying capacity of steel columns and beams was studied by Pessiki et al. [5] and Kang et al. [6], respectively. These studies concluded that the capacity of beams and columns is highly dependent on the location of insulation damage and that the removal of even a small part of insulation leads to a dramatic increase of steel temperatures in columns and beams and severely decreases the load capacity of columns and beams.

In the previous studies, only detailed complex numerical simulations were presented as tools to study the effect of insulation loss on the temperature and load capacity of steel members. In this paper, a simplified method is developed for tracing the effect of partial loss of the fire insulation on the temperature profile of steel member exposed to fire. Also, the method developed in this study can be useful in post-fire investigation, where for instance, the maximum steel temperature need to be estimated after a fire that has been caused by an accident which resulted in a partial loss of insulation. Such simple method can facilitate reliable assessment of cross-sectional steel temperature without the need for using complex finite element modeling that requires skilled expertise.

\section{Effect of Insulation Loss}

When a part of insulation is lost, heat flow through that region will increase significantly leading to localized sudden rise in steel temperature in that region. Due to high conductivity of steel, this local rise of temperature then spreads into the rest of the cross section and thus the average temperature of steel rises. Therefore, partial loss of insulation leads to faster rate of strength and stiffness degradation of steel and the structural member.

Further, uneven loss of insulation leads to development of high temperature gradients across the steel section. Such temperature gradients generate two major effects; first, thermal gradient leads to thermal bowing (lateral deflection) if the member is not rotationally restrained. However, if the member is rotationally restrained, then bending moments will develop in the member due to restraint of thermal bowing. Second, thermal gradient causes a non-uniform distribution of steel stiffness across the section. This inhomogeneity of steel mechanical properties leads to a shift in the center of stiffness from its original location at the center of gravity towards the cooler regions on the cross section. The consequences of thermal gradient that is induced by partial loss of insulation include the development of additional bending moments due to the local $\mathrm{P}-\delta$ effect from either thermal bowing or migration of center of stiffness, or both effects.

Such fire induced moments are to be given due consideration in evaluating fire response of structural members, and for this, the effect of thermal gradient that develops in the cross section due to a partial loss of insulation is to be quantified. In the next sections, the governing heat transfer equation will be introduced, from which a simple method will be developed for computing temperature rise due to partial loss of insulation. 


\subsection{Heat Transfer Equation}

The governing partial differential equation for heat transfer within the cross section of a structural member (beam, column, etc.) can be written as [7]:

$$
\rho c \frac{d T}{d t}=\nabla \cdot(k \nabla T)
$$

where $\rho c=$ heat capacity, $T=$ temperature, $t=$ time, and $\nabla=$ is the spatial gradient operator, and $k=$ conductivity matrix.

At the fire-member (e.g. beam) interface, heat is transferred through radiation and convection. The heat flux on the boundary due to radiation $q_{\mathrm{rad}}$ is generally governed by Stefan-Boltzmann law:

$$
q_{\text {rad }}=\sigma \varepsilon_{e}\left(T^{4}-T_{f}^{4}\right)
$$

where $\sigma=$ Stefan-Boltzmann constant $=5.67 \times 10^{-8}\left(\mathrm{~W} / \mathrm{m}^{2}{ }^{\circ} \mathrm{K}^{4}\right)$, and $\varepsilon_{e}$ is the effective emissivity of the exposed surface and it is related to the "visibility" of the surface to the fire $[7,8] . T_{f}$ is temperature of the atmosphere surrounding the boundary (in this case it is the fire temperature). The factor $\varepsilon_{e}$ generally varies between 0.5 and 1.0 depending on the material and nature of the surface and the flames of fire. For steel members that are directly exposed to indoor fire, emissivity can vary between 0.7 and 0.9 . The less "severe" exposure conditions (i.e., situations where heat flux from radiation is less), such as exposure to external fire outside building façade or rougher surfaces, such as insulation or concrete surfaces, the emissivity can be between 0.3 and $0.7[7,9]$.

Heat flux transferred through convection $q_{c o n}$ is generally governed by Newton's law of cooling:

$$
q_{c o n}=h_{c}\left(T-T_{f}\right)
$$

where $h_{c}$ is the convective heat transfer coefficient and it varies between $20 \mathrm{~W} /$ $\mathrm{m}^{2}{ }^{\circ} \mathrm{C}$ and $35 \mathrm{~W} / \mathrm{m}^{2}{ }^{\circ} \mathrm{C}$ for typical fire exposures. This factor also depends on the atmospheric conditions of the fire and the type of exposure of the surface to the fire. If the surface is directly exposed to fire, such as the bottom flange of steel beams, the value of $h_{c}$ tends to be high. If the surface is far from direct exposure, such as the case with steel connections or gaps, values of $h_{c}$ can be as low as $15 \mathrm{~W} / \mathrm{m}^{2}{ }^{\circ} \mathrm{C}$ [7].

The heat flux and temperature gradient in any medium are generally related through Fourier's law of conduction:

$$
q=-k \nabla T
$$

Using Fourier's law, the governing heat transfer equation on the boundary of the beam can be expressed as: 


$$
k\left(\frac{\partial T}{\partial y} n_{y}+\frac{\partial T}{\partial z} n_{z}=-q_{b}\right)
$$

where $n_{y}$ and $n_{z}$ are components of the vector normal to the boundary in the plane of the cross-section. The right hand side of Equation 5 is dependent on the type of boundary condition.

\subsection{Simplified Approach}

In order to account for the effect of partial loss of insulation on steel temperature, consider a steel plate covered with uniform spray-applied fire proofing material of thickness $t_{p}$ as shown in Figure 1. The heated perimeter through which the insulation is in contact with the steel plate is denoted as $F_{p}$. If we assume that a percentage $(p)$ of the insulation cross-sectional area $A_{p}$ is lost due to some reason, then the length of the lost protection $\left(\ell_{p}\right)$ is computed as $\left(A_{p} / t_{p}\right) \times p$ as shown in Figure 1.

The total heat that is transferred to the plate is comprised of two parts, heat due to radiation $Q_{\mathrm{rad}}$ and heat due to convection $Q_{\text {con }}$. Based on conservation of energy, the incoming heat should equal the heat stored in the insulation $H_{p}$ and in steel $H_{s}$, that is:

$$
H_{p}+H_{s}=Q_{c o n}+Q_{r a d}
$$

The heat stored in insulation and steel can be computed, per unit depth of the plate, as:

$$
H_{p}+H_{s}=\rho_{p} c_{p} t_{p}\left(F_{p}-\ell_{p}\right)\left(\frac{\Delta T_{f}+\Delta T}{m}\right)+\rho_{s} c_{s} A_{s} \Delta T
$$

where $\rho_{p} c_{p}$ and $\rho_{s} c_{s}$ are the heat capacity of insulation and steel, respectively. In Equation 7, the temperature on the surface of the insulation was assumed to be equal to the fire temperature. Also, it was assumed that the temperature in the

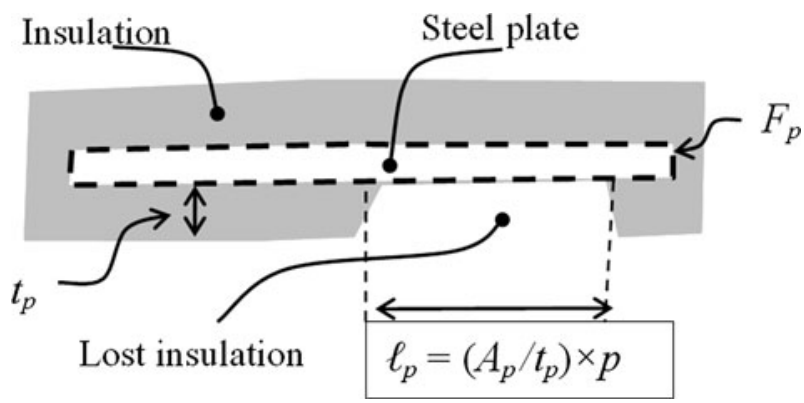

Figure 1. Cross section of steel plate with partial loss of insulation. 
protection is an average of the fire and steel temperatures, i.e. $\left(T_{f}+T\right) / m$, where $m=2$ for linear variation.

The heat transferred to the plate can be computed, per unit depth of the plate, as:

$$
Q_{c o n}+Q_{r a d}=\left[\left(h_{c} \ell_{p}+k_{p} / t_{p}\right)\left(F_{p}-\ell_{p}\right)\left(T_{f}-T\right)+\ell_{p} \sigma \varepsilon_{e}\left(T_{f}^{4}-T^{4}\right)\right] \Delta t
$$

where $k_{p}$ is the thermal conductivity of the insulation material. The heat transferred due to convection in Equation 8 is computed due to convection through exposed steel $\left(\ell_{p}\right.$, i.e. where insulation is damaged) only. Convection and radiation is neglected on the surface of the insulation $\left(F_{p}-\ell_{p}\right.$, i.e. where insulation is intact $)$ simply because the temperature on that surface is assumed to be equal to the fire temperature $\left(T_{f}\right)$. Therefore, the heat flux on the boundary $\left(F_{p}-\ell_{p}\right)$ between insulation and the steel plate is computed in Equation 8 using Fourier's law of conduction (Equation 4) and assuming linear gradient of temperature across the insulation.

Combining Equations 7 and 8 and solving for the change in steel temperature leads to the following relationship:

$$
\Delta T=\frac{\left(F_{p}-\ell_{p}\right) / A_{s}}{\frac{t_{p}}{k_{p}} \rho_{s} c_{s}\left(1+\frac{\phi}{m}\right)}\left\{\left(1+h_{c} \ell_{p}\right)\left(T_{f}-T\right)+q_{r}\right\} \Delta t-\frac{\Delta T}{1+\frac{m}{\phi}}
$$

with $\phi=\frac{\rho_{p} c_{p} t_{p}}{\rho_{s} c_{s}}\left(\frac{F_{p}-\ell_{p}}{A_{s}}\right)$ and $q_{r}=\frac{\ell_{p}}{\left(F_{p}-\ell_{p}\right)}\left(t_{p} / k_{p}\right) \sigma \varepsilon_{e}\left(T_{f}^{4}-T^{4}\right)$. Obviously, Equation 9 assumes a single exposed plate (with lost insulation) that is not connected to other plates of the cross section. However, it will be shown that the assumptions made above are sufficient to arrive at a reasonable estimation of average temperature rise in the exposed plate.

On the other hand, the temperatures in the other plates of the cross section will be affected by the localized rise in temperature of the exposed plate. Obviously, due to the high conductivity of steel, more heat will flow to the other plates from the plate of concentrated temperature rise where insulation was lost. The approach above does not incorporate thermal conductivity of steel since it considers steel to have a uniform temperature. However, to account for the flow between the exposed plate and the other plates, a corrective factor $(\alpha)$ is introduced and is used for the other plates. Using similar approach as the one above, temperature change in the other steel plates can be computed as:

$$
\Delta T=\frac{\alpha F_{p} / A_{s}}{\frac{t_{p}}{k_{p}} \rho_{s} c_{s}\left(1+\frac{\phi}{m}\right)}\left(T_{f}-T\right) \Delta t-\frac{\Delta T}{1+\frac{m}{\phi}}
$$

with $\phi=\frac{\rho_{p} c_{p} t_{p}}{\rho_{s} c_{s}}\left\{\alpha \frac{F_{p}}{A_{s}}\right\}$, and the factor $\alpha$ in Equation 10 is introduced to account for the heat flow from the exposed (hotter) plate, where insulation is lost, to the other plates of the cross section.

Based on intensive numerical studies, the factor $\alpha$ is affected primarily by the change in thermal properties of steel with temperature and the differential in the 
heat stored in the exposed plate and the rest of the plates of the section. The thermal conductivity of steel drops to half after reaching $700^{\circ} \mathrm{C}$, and specific heat of steel also rises significantly after such temperature. The differential in stored energy in the exposed plate and the other plates of the cross section can be related to the excessive heat transferred to the exposed plate through the insulation gap $\left(\ell_{p}\right)$. This is justified in case of 4-side exposure, where the cross section tends to have a uniform temperature distribution. Thus, introducing a gap in the insulation will lead to a gradient in the heat stored in the steel plates.

Therefore, to compensate for the heat flow from the steel plate where the insulation is damaged, regression analysis was conducted to estimate the correction factor $\alpha$. The results of numerical analysis on a wide range of steel cross sections, with different ratios of damaged insulation were normalized to the results from analysis on the same set of cross sections but with fully intact insulation. Based on the results of numerical studies, the factor $\alpha$ is assumed to attain these values:

$$
\alpha= \begin{cases}2.0+\frac{\ell_{p}}{\left(F_{p}\right)_{\text {exp }}} & T \leq 700^{\circ} \mathrm{C} \\ 1.0 & T>700^{\circ} \mathrm{C}\end{cases}
$$

where $\left(F_{p}\right)_{\text {exp }}$ is the heated perimeter of the exposed plate (with partial loss of insulation).

Eurocode 3 [10] provides a relation for computing temperature in fully protected steel members. Eurocode relation is given as:

$$
\Delta T=\frac{F_{p} / A_{s}}{\frac{t_{p}}{k_{p}} \rho_{s} c_{s}}\left(\frac{T_{f}(t)-T(t)}{1+\frac{\phi}{3}}\right) \Delta t-\left(e^{\phi / 10}-1\right) \Delta T_{f}
$$

where $\phi=t_{p} \frac{\rho_{p} c_{p}}{\rho_{s} c_{s}} \frac{F_{p}}{A_{s}}$ and $m=3$. The term $\left(e^{\phi / 10}-1\right)$ is suggested by Eurocode to provide better correlation with test data. This equation is quite similar to Equation 9 but cannot be used as it is for computing temperature in steel members with damaged or lost insulation. Therefore, Equation 12 can be adjusted by replacing the section factor $F_{p} / A_{s}$ with the reduced section factor $\left(F_{p}-\ell_{p}\right) / A_{s}$ and then incorporating the heat fluxes due to convection $h_{c} \ell_{p}\left(T_{f}-T\right)$ and radiation $q_{r}$ as seen in Equation 9.

\section{Numerical Analysis}

In order to verify the validity of the approach developed above, predictions from the proposed equations are compared to results from rigorous finite element analysis. The finite element model for thermal analysis is developed using ANSYS [11] and is presented below.

\subsection{Thermal Analysis}

A steel cross section of an I-beam is modeled for heat transfer analysis using ANSYS [11]. The thermal mesh was created using two types of elements, namely 
PLANE55 and SURF151. PLANE55 is a plane element with two-dimensional thermal conduction capability and has four nodes with a single degree of freedom, namely temperature, at each node. The element is applicable to a two-dimensional, steady-state or transient thermal analysis. SURF151 element is generally used to account for various load and surface effect applications. In the current analysis, SURF151 element was overlaid onto the face of PLANE55 2D thermal solid element to simulate the effect of thermal radiation from ambient air to steel section.

The cross-section was meshed with PLANE55 element, while the exposed boundaries of the cross-section were meshed using SURF151 elements. Both heat convection and radiation loads were applied at the exposed boundaries of the section (on SURF151 elements). A convection coefficient of $h_{c}=25 \mathrm{~W} /\left(\mathrm{m}^{2}{ }^{\circ} \mathrm{C}\right)$ was assumed in the analysis based on the recommendation in literature $[7,9,12,13]$ and in codes [14]. Different values of effective emissivity factor $\left(\varepsilon_{e}\right)$ were used depending on the exposure boundary [7]. For the outer side surfaces of the flanges the value of $\varepsilon_{e}$ was 0.7 and for the internal sides of the web and flanges the value of $\varepsilon_{e}$ was 0.5 . The Stefan-Boltzmann radiation constant of $\sigma=5.67 \times$ $10^{-8} \mathrm{~W} /\left(\mathrm{m}^{2} \mathrm{~K}^{4}\right)$ was used in the analysis and the ambient (bulk) temperature $\left(T_{\infty}\right)$ surrounding the faces of SUR151 element was assumed to be equal to the fire temperature $\left(T_{f}\right)$.

\subsection{High Temperature Thermal Properties}

The temperature-dependent thermal properties of steel that are used in the thermal analysis model are according to the Eurocode constitutive models [10]. Figure 2 shows the variation of thermal conductivity and heat capacity of structural steel as a function of temperature. While the thermal conductivity of steel drops linearly until $800^{\circ} \mathrm{C}$, heat capacity undergoes small increase until a sudden increase in heat capacity occurs at around $750^{\circ} \mathrm{C}$. The peak in heat capacity of

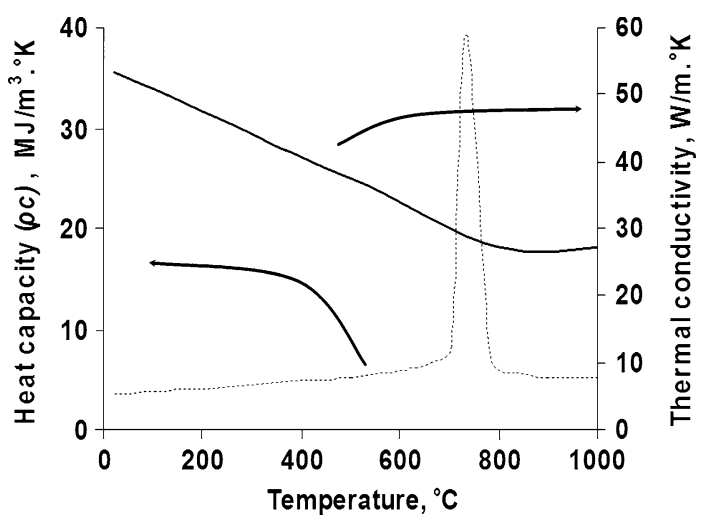

Figure 2. Thermal properties of structural steel according to Eurocode 3. 


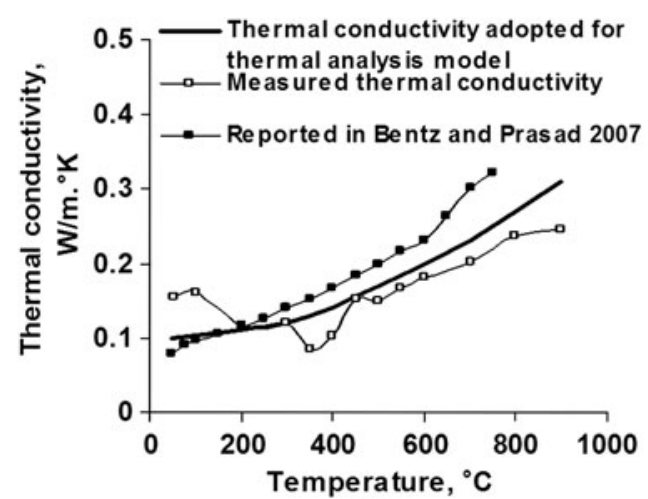

(a)

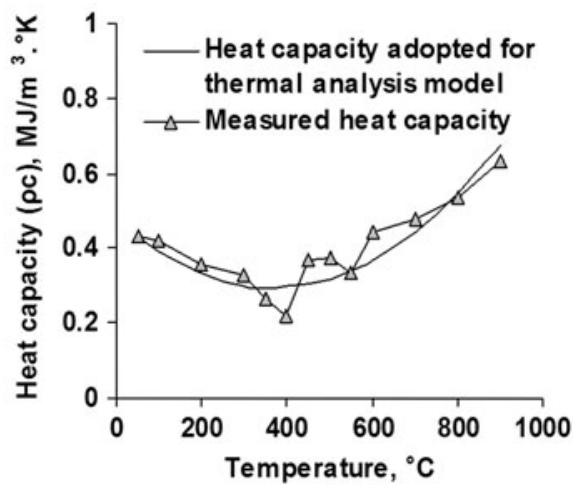

(b)

\section{Figure 3. Temperature dependent thermal properties of the insula- tion material. a Thermal conductivity $\left(k_{p}\right)$. b Heat capacity $\left(\rho_{p} c_{p}\right)$.}

steel at $750^{\circ} \mathrm{C}$ can be attributed to the phase change that occurs in steel at such high temperature, which results in absorption of huge amount of energy.

For the insulation used in the thermal analysis, the thermal properties are plotted in Figure 3 as function of temperature. The insulation material whose properties are presented in the figure is CAFCO300 [15], and it is a typical cementitious fire proofing material that is spray-applied on steel members. This insulation material has been used in the fire tests that are used for the validation of the thermal analysis model as presented in the next section.

Both thermal conductivity and heat capacity of the insulation material were directly measured at various temperatures using Hot Disk "TPS2500" [16] test apparatus which measures these properties as per ISO/DIS22007-2 specifications [17].

Thermal conductivity and specific heat tests were carried out using Hot Disk is connected to an electric furnace through which a specimen can be subjected to increasing temperature up to $735^{\circ} \mathrm{C}$. This state-of-the-art test equipment utilizes a flat plate sensor through transient plane source (TPS) technique to measure thermal conductivity and specific heat in $20^{\circ} \mathrm{C}$ to $735^{\circ} \mathrm{C}$ range [17]. The sensors are made-up of electricity-conducting double spiral shaped nickel foil, insulated with $25 \mu \mathrm{m}$ thick layer of either kapton or mica sensors. Kapton sensor can be used for measurements up to $200^{\circ} \mathrm{C}$, whereas mica sensor has to be used for measurements in $100^{\circ} \mathrm{C}$ to $735^{\circ} \mathrm{C}$. The sensor, when sandwiched between two halves of specimen, acts as a heat source, as well as detector, and reads input and output voltage signals. During high temperature thermal property tests, specimen and sensor assembly is kept in electric furnace that is connected to the Hot Disk. The furnace generates specified temperature in the specimen and the sensor records thermal conductivity and specific heat at the target temperature.

Kapton sensor was used to undertake tests at room temperature $\left(20^{\circ} \mathrm{C}\right)$ and mica sensor was used for the remaining temperature points from $100^{\circ} \mathrm{C}$ to $735^{\circ} \mathrm{C}$. The sensor, sandwiched between two halves of the specimen and the assembly, is 
exposed to high temperature generated in the electric furnace connected to Hot Disk apparatus. The test condition parameters namely, probing depth, sensor type, initial thermal coefficient of resistance (TCR), hold time at steady state, measurement power, and measurement times are to be programmed (as input) into Hot Disk apparatus by user. For these tests, initial TCR of $0.004698 / \mathrm{K}$, probing depth of $15 \mathrm{~mm}$, sensor measurement power of $1.0 \mathrm{~W}$, hold time of $30 \mathrm{~min}$ and measurement time of $40 \mathrm{~s}$ was used. For high temperature measurements, a builtin value of TCR at each temperature as per sensor type was used. At each target temperature, once the thermal equilibrium is attained, thermal conductivity and specific heat are recorded. The temperature then goes to next target temperature for new measurements.

The measured thermal conductivity is compared to data from literature [18] in Figure 3a. Results indicate that thermal conductivity of the insulation generally increases with temperature, probably due to the shrinkage of the SFRM material under heating, while the heat capacity (Figure 3b) first decreases slightly to $400^{\circ} \mathrm{C}$, then increases again with temperature. The initial decrease in the heat capacity is attribute to the phase changes in the material. It is worth mentioning that the TPS method can skip the effect of the moisture evaporation on the heat capacity of the SFRM, and thus, careful attention should be taken when using the measured properties. This however does not affect the proposed method since the method is incremental and can employ variable temperature-dependent thermal properties of SFRM and/or steel. The differences between the different measured values of thermal conductivity can be ascribed to differences in test methods or environmental parameters, such as moisture content of the insulation on the day of test, in addition to the differences in chemical composition of different types of SFRMs. Therefore, based on that comparison, a representative "smooth" curve for thermal conductivity as function of temperature is adopted for thermal analysis and is shown in Figure 3b. Similarly, the recorded heat capacity was smoothened via a polynomial function for efficient input for the thermal analysis model.

\subsection{Modeling Insulation Damage}

Since the parameters of convection and radiation heat fluxes across the region where insulation is partially lost or damaged are not precisely known, an indirect approach is used to model the loss of insulation. This approach is based on replacing the insulation gap with a hypothetical material that has much higher conductivity and much lower heat capacity than those of the original insulation material. The surface of that material (where insulation is lost) is assumed to continue to have the same heat convection and radiation parameters as those of the cross section.

In order to determine how much to amplify the conduction properties of the hypothetical material, a comparison is made between the model predictions and published data obtained from fire tests. This process is shown in the validation of the thermal model in the next section. It is worth mentioning that this is a crude method for modeling insulation damage/loss. This approach is justified because of 
the lack of information on the heat transfer parameters (convection/radiation) on the area of damaged/lost insulation.

\subsection{Validation of ANSYS Thermal Model}

There is a lack of fire tests on steel members with damaged insulation. Recently, fire resistance tests on steel beam-columns were carried out at Michigan State University [19], wherein the insulation was scraped (removed) on one side of the beam-columns. The fire resistance tests, conducted on four insulated beam-columns of $\mathrm{W} 8 \times 48$ sections, were aimed at studying the effect of thermal gradient on beam-column response. These beam-columns were of A992 Grade 50 steel (measured average $F_{y}=345 \mathrm{MPa}$ ) and had a length of $3.3 \mathrm{~m}$. The specimen dimension, thermal mesh and insulation scheme are shown in Figure 4. Full details of the fire resistance experiments, including test procedure, instrumentation, and detailed measurements are presented elsewhere [19].

The applied insulation was uniform with an average thickness of $40 \mathrm{~mm}$. The spray-applied fire resistant material (SFRM) that was used is CAFCO 300 [15] and its thermal properties (thermal conductivity and heat capacity) are plotted in Figure 3 as function of temperature. Thermal gradients were generated by removing the insulation material at specific location as shown in Figure 4a. Figure $4 b$ shows the thermal mesh, where the cross section was meshed using PLANE55 elements and the exposed boundary with SURF151 elements.

The insulation gap was modeled using a higher conducting hypothetical insulation material as explained earlier. The resulting temperature distribution after $60 \mathrm{~min}$ of fire exposure is shown in Figure 4c, which shows a high thermal gradient across the section and higher temperature near the insulation gap.

A comparison between the results of ANSYS model and measured temperatures in the fire test is shown in Figure 5. Since the insulation loss was modeled using a higher conducting hypothetical material, the thermal properties of such material need to be calibrated. The thermal properties of the damaged insulation (hypothetical material) were "degraded" to 3 and 5 times of the original thermal properties of the insulation and then the results were compared to the recorded temperatures. Figure 5a shows that the results obtained of using $\left(k_{p}\right)_{\text {Damaged }}=$ $3 \times\left(k_{p}\right)_{\text {Original }}$ for the hypothetical material led to a good agreement with the temperatures recorded in the test. However, using $\left(k_{p}\right)_{\text {Damaged }}=5 \times\left(k_{p}\right)_{\text {Original }}$ for the damaged insulation resulted in higher temperature in the steel section as shown in Figure $5 b$. This is primarily due to the higher conduction in the region with lost insulation. Therefore, using $\left(k_{p}\right)_{\text {Damaged }}=3 \times\left(k_{p}\right)_{\text {Original }}$ as a "degradation ratio" for the modeling the insulation gap leads to better predictions. Also, predictions from the proposed approach (Equations 9, 10) are compared to test data in Figure 5c. The comparison shows that the proposed approach provide conservative estimates of steel temperature, especially in the flange with damaged insulation. Overall, the comparison shows that the thermal model in ANSYS and the proposed approach are capable of predicting temperatures in steel members with local insulation damage within a sufficient accuracy. 


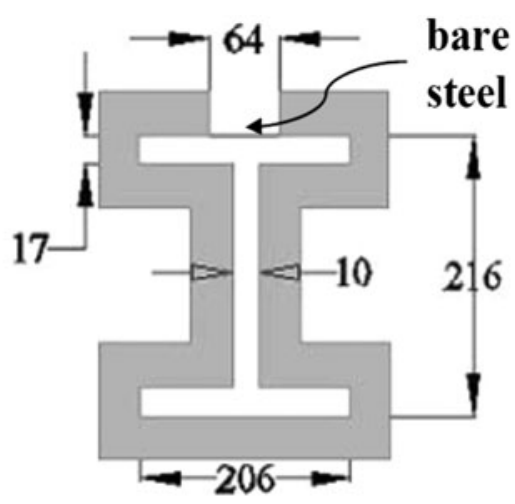

(a)

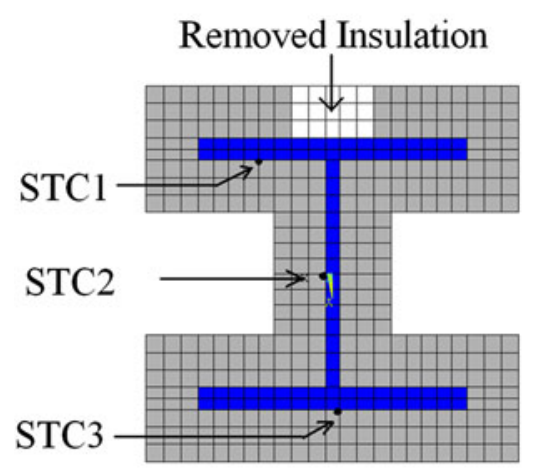

(b)

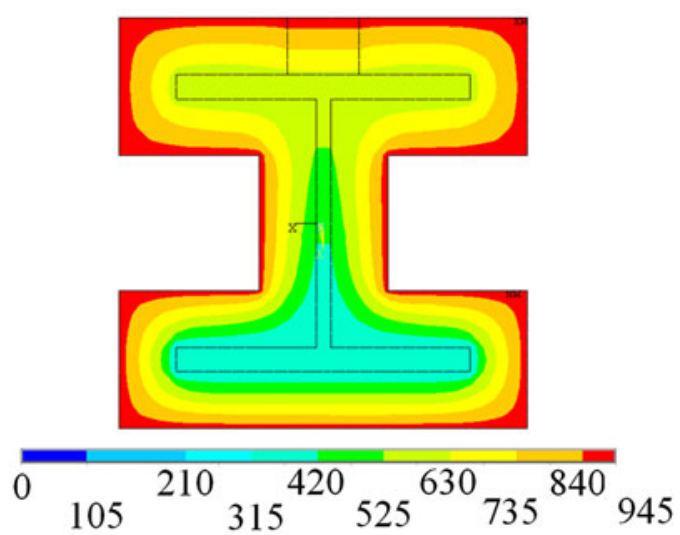

(c)

Figure 4. Dimensions, thermal mesh and temperature confour of the tested specimen. a Cross section dimensions with $40 \mathrm{~mm}$ average insulation thickness. $b$ Thermal mesh, thermocouples and lost insulation. c Temperature gradient at $t=60 \mathrm{~min}$. 


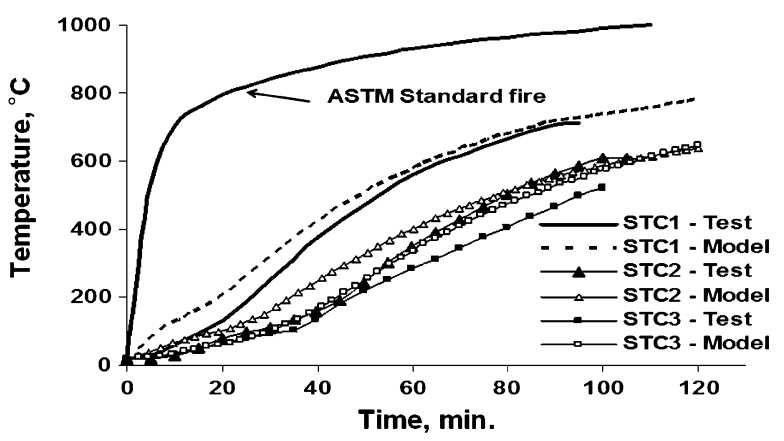

(a)

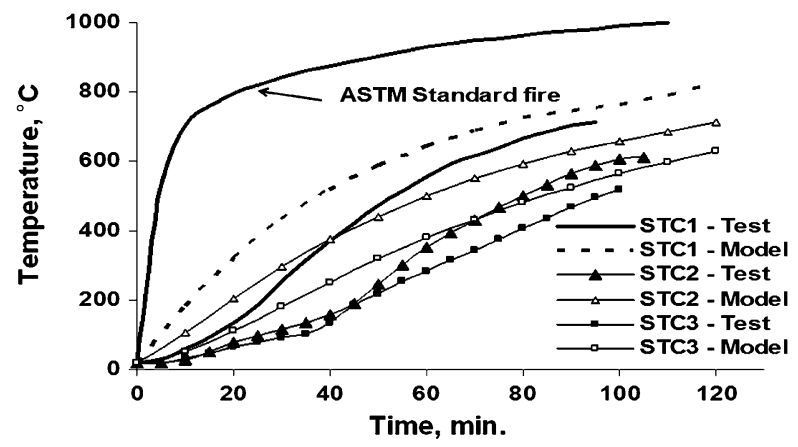

(b)

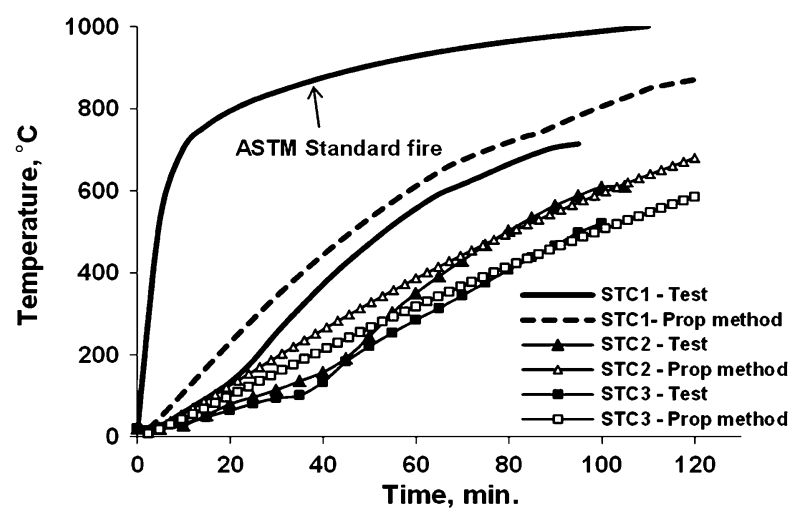

(c)

Figure 5. Temperature in steel using different damage properties of insulation. a ANSYS model vs. test data using $\frac{\left(k_{p}\right)_{\text {Damaged }}}{\left(k_{p}\right)_{\text {original }}}=3$ and $\frac{\left(\rho_{\mathbf{p}} \boldsymbol{c}_{\mathbf{p}}\right)_{\text {original }}}{\left(\rho_{\mathbf{p}} \boldsymbol{c}_{\mathbf{p}}\right)_{\text {Damaged }}}=\mathbf{3}, \boldsymbol{b} \frac{\left(\boldsymbol{k}_{\mathbf{p}}\right)_{\text {Damaged }}}{\left(\boldsymbol{k}_{\boldsymbol{p}}\right)_{\text {Original }}}=\mathbf{5}$ and $\frac{\left(\rho_{\mathbf{p}} \boldsymbol{c}_{\mathbf{p}}\right)_{\text {Original }}}{\left(\rho_{\mathbf{p}} \boldsymbol{c}_{\mathbf{p}}\right)_{\text {Damaged }}}=\mathbf{5}, \mathbf{c}$ Test data compared to predictions from the proposed method. 


\section{Validating the Proposed Approach}

For validating the proposed approach, temperatures obtained from Equations 9 and 10 are compared with results generated from finite element analysis. Equation 9 is used to predict temperature in the exposed plate with partial loss of insulation, while Equation 10 is used for the other plates. Two cases are considered. Case one is with a part of the insulation removed from the flange, and case two is with part of the insulation removed from the web. In each case, the ratio $(p)$ of the removed insulation area to the total insulation area was varied from $3 \%$ to $10 \%$. The two cases are illustrated in Figure 6 which shows the meshed sections with the corresponding insulation areas removed from either flange or web. The cross section selected for analysis is a typical W14 $\times 311$ [20] column exposed to fire from four sides. The results of the comparison are presented in Figures 7, 8, 9 , and 10 .

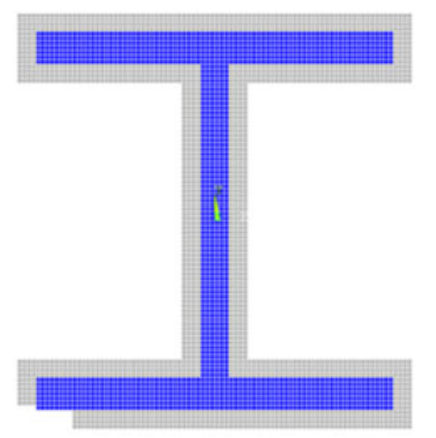

$$
p=3 \%
$$

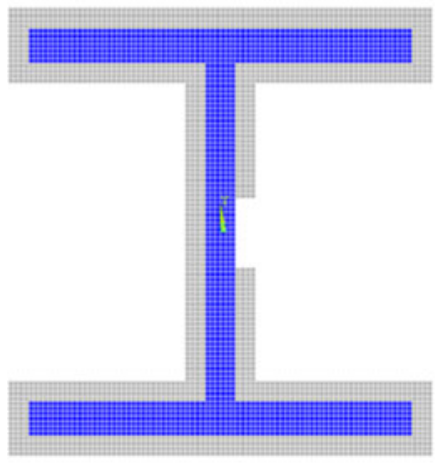

$$
p=3 \%
$$

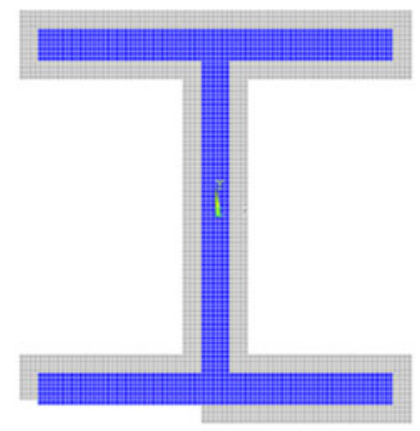

$$
p=10 \%
$$

(a)

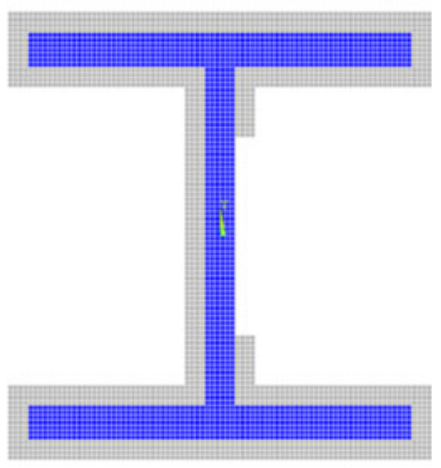

$$
p=10 \%
$$

(b) 


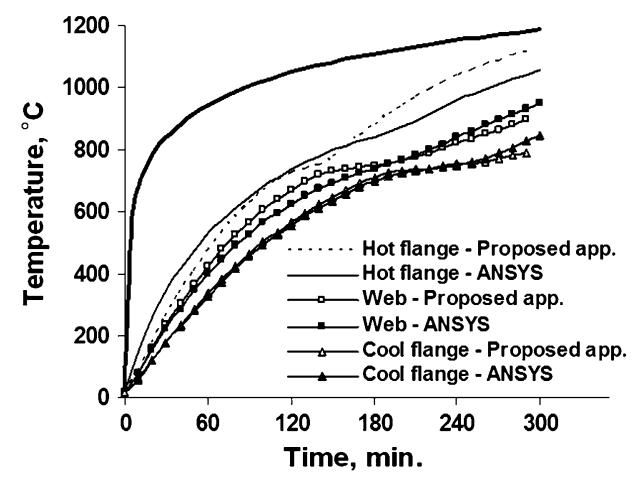

(a)

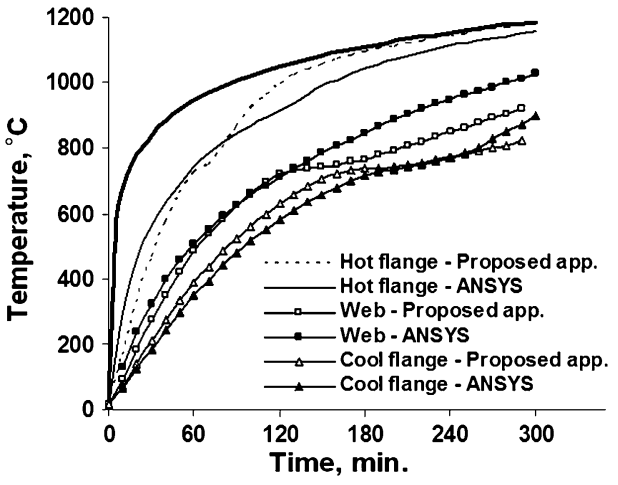

(b)

Figure 7. Steel temperafure in W14 × 311 cross section with $12.7 \mathrm{~mm}$ insulation, 4-sided fire exposure, with insulation loss in the flange. $a p=3 \%$. $b p=10 \%$.

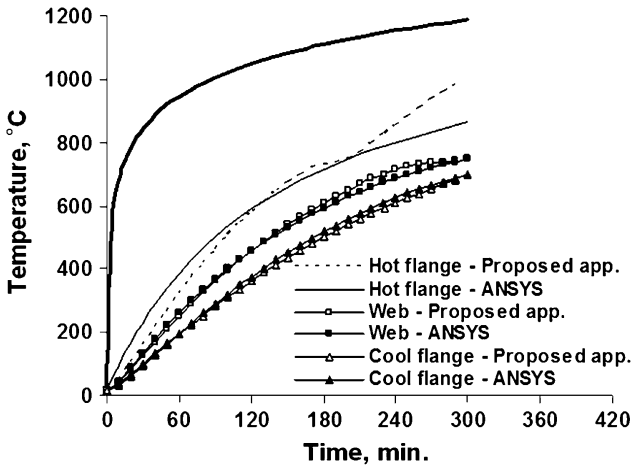

(a)

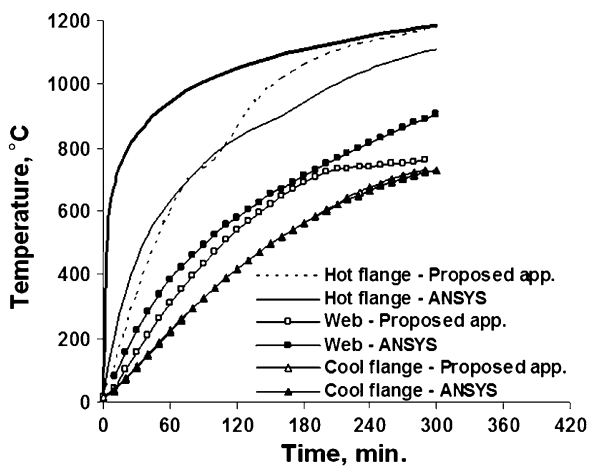

(b)

Figure 8. Steel temperature in W14 1311 cross section with $25.4 \mathrm{~mm}$ insulation, 4-sided fire exposure, with insulation loss in the flange. $a p=3 \%$. $b p=10 \%$.

\subsection{Insulation Loss in the Flange}

Figures 7 and 8 show steel temperature developed in the column in the case of lost insulation in the flange of the column. It can be seen in the figures that a thermal gradient develops in the cross section due to the loss of insulation, with higher temperature in the flange where the insulation is lost. The thermal gradient increases with the increase of the lost insulation area. Losing 3\% of the insulation area in the flange leads to $200^{\circ} \mathrm{C}$ thermal gradient, as shown in Figure 7a. Further, if the lost insulation area in the flange increases to $10 \%$, the thermal gradient in the section increases to $400^{\circ} \mathrm{C}$, as shown in Figure $7 \mathrm{~b}$. 


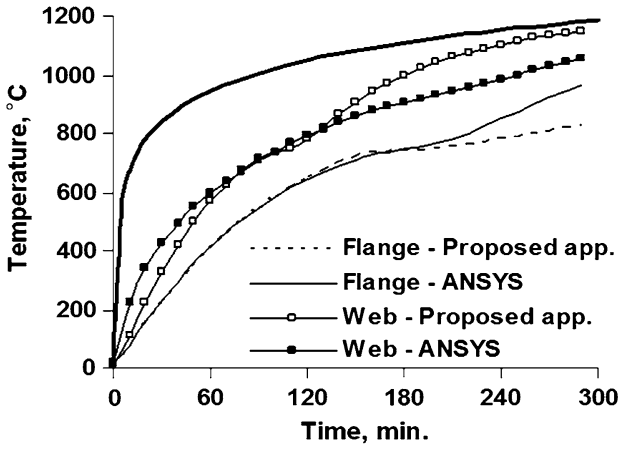

(a)

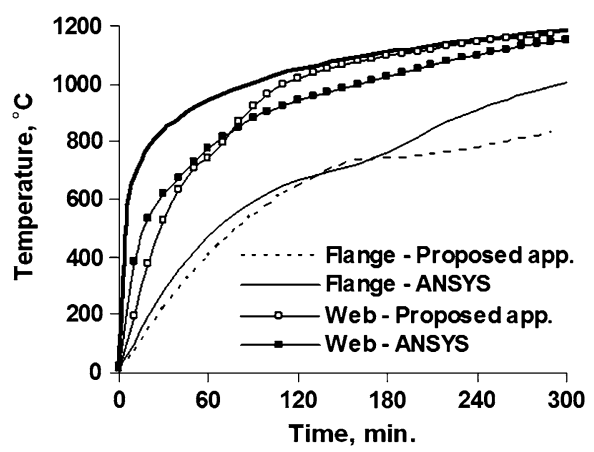

(b)

Figure 9. Steel temperature in W14 × 311 cross section with $12.7 \mathrm{~mm}$ insulation, 4-sided fire exposure, with insulation loss in the web. $a p=3 \%$. $b p=10 \%$.
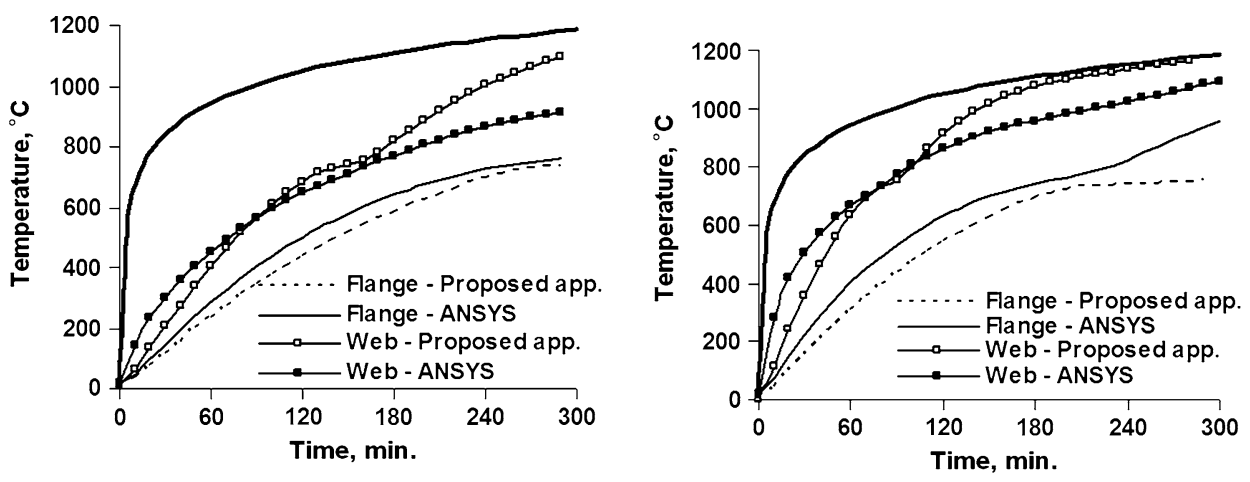

Figure 10. Steel temperature in W14 × 311 cross section with $25.4 \mathrm{~mm}$ insulation, 4-sided fire exposure, with insulation loss in the web.

The results predicted using the proposed approach (Equations 9, 10) compare well with the results obtained from ANSYS. Similar trend can be seen in Figure 8, which shows the effect of insulation loss on steel temperature but with increased insulation thickness to $25.4 \mathrm{~mm}$. Based on comparison between Figures 7 and 8, it seems that the insulation thickness has small effect on the thermal gradient developed due to the insulation loss. This observation was mentioned in previous studies $[3,4]$. The reason behind such behavior can be attributed to the fact that, in case of insulation loss, the thermal gradient that develops in the section is mainly due to the influx of temperature through the gap of insulation, and thus depends mainly on the exposed length where insulation is removed rather than on the insulation thickness. 


\subsection{Insulation Loss in the Web}

Figures 9 and 10 show the effect of losing insulation in the web of the cross section on the steel temperature. In the figures, only the web and flange temperatures are reported due to the symmetry of results in the flanges. As expected, losing some of the insulation that covers the web leads to a rapid rise in temperature in that region. This is seen in Figure 9a, b, where the temperature of the web is higher with larger insulation loss. Also, comparing Figure 9a, b indicates that larger insulation loss leads to higher difference between web and flange temperature, obviously due to higher influx of heat to the exposed web. Further, comparing the results in Figure 9a to those in Figure 10a, which shows the same results but with thicker insulation, leads to a conclusion that the insulation thickness has little influence on the difference between the web and flange temperatures. This can be attributed to the fact that the heat influx through the insulation gap is a function of the exposed length $\left(\ell_{p}\right)$ rather than the thickness of the insulation.

On all cases, the results obtained using the proposed approach seems to be in a good comparison with those obtained from ANSYS. The proposed approach tends to overestimate the temperature in the exposed plate (the web) at temperatures higher than $800^{\circ} \mathrm{C}$. This can be attributed to the differences in the heat transfer mechanism between the simplified approach and the finite element method. While the finite element method approach models the insulation loss/gap as a higher conducing material, the proposed approach accounts for radiation and convection heat fluxes. It is hard to determine the exact values of effective emissivity $\left(\varepsilon_{e}\right)$ and convective heat transfer coefficient $\left(h_{c}\right)$ in the area of lost insulation. The values of $\varepsilon_{e}$ and $h_{c}$ that were used in the proposed approach (in Equation 9 for that region) were $0.3 \mathrm{~W} / \mathrm{m}^{2}{ }^{\circ} \mathrm{C}$ and $15 \mathrm{~W} / \mathrm{m}^{2}{ }^{\circ} \mathrm{C}$, respectively. The correlation between the experimental and the theoretical values of $\varepsilon_{e}$ and $h_{c}$ in case of damaged/lost insulation requires intensive tests and is beyond the scope of this study. The aim of this study is to present a simplified approach that is capable of predicting the temperature profile in steel section when it suffers a loss in fire protection.

As it was explained earlier, the partial loss of insulation have a significant impact on the bearing capacity and hence fire resistance of structural members. This effect will be discussed through an example in the following section, where the applicability of the above computed steel temperatures to determine the sectional capacity of steel members is illustrated.

\section{Design Applicability}

In order to illustrate the applicability of the proposed approach in fire resistance assessment or design situation, an example is presented herein. A steel column of AISC section W14 $\times 145$ [20], with $25.4 \mathrm{~mm}$ uniform spray applied fire protection material is exposed to fire from four sides and suffers a loss of $5 \%$ of fire protection in one of the flanges of the column, as shown in Figure 6a. The insulation properties are assumed to be similar to those presented in this paper. The proposed approach (Equations 9,10) is used to compute the temperature in the three 


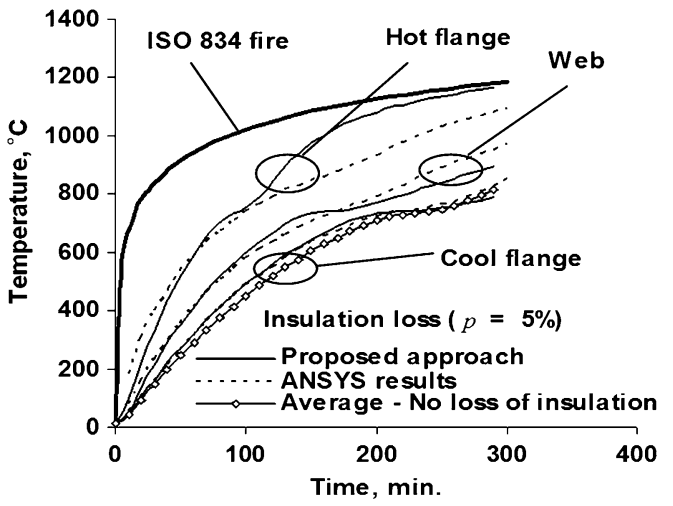

(a)

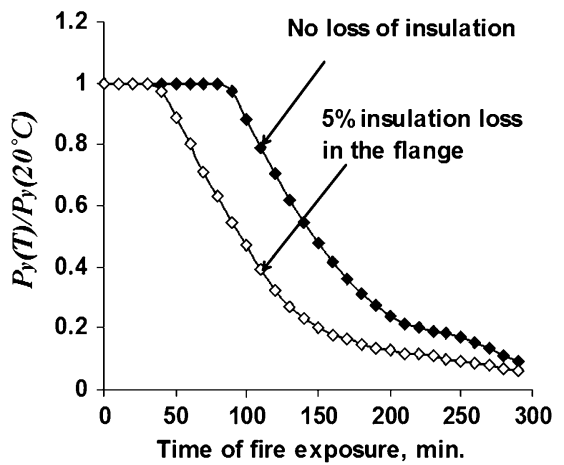

(b)

\section{Figure 11. Effect of insulation loss on the temperature and capacity of steel column. a Steel temperature. b Plastic and axial capacity.}

plates of the section. Figure 11a plots the temperatures obtained using the proposed approach and from ANSYS for the three plates of the section. Also, the average temperature of the section assuming no insulation loss is plotted in Figure 11a. The faster rise in temperature of the section due to the loss of $5 \%$ insulation can be readily seen in Figure 11a when compared to the average temperature with fully intact fire protection.

Figure 11b shows the reduction in the plastic axial capacity of the column as function of fire exposure time. The axial capacity is computed as $P_{y}(T)=\sum F_{y}\left(T_{\text {plate }}\right) A_{\text {plate }}$ and using the mechanical properties of steel as specified in Eurocode 3 [10]. As it can be seen in Figure 11b, 5\% loss of insulation results in a severe reduction in the carrying capacity of the column. The results indicate that if the insulation is fully intact, the column retains its axial plastic capacity for $100 \mathrm{~min}$ of fire exposure. However, the capacity drops to $50 \%$ after $100 \mathrm{~min}$ of exposure when $5 \%$ of insulation is lost.

Based on Figure 11a, if the applied axial load on the column above was $50 \%$ of its room temperature axial capacity, the column with fully intact fire protection will have $3 \mathrm{~h}$ of fire resistance, but if the same column suffers $5 \%$ insulation loss in the flange, the fire resistance drops to $90 \mathrm{~min}$.

\section{Conclusions}

Based on this study, the following conclusions can be drawn:

1. Partial loss of fire insulation causes rapid rise in steel temperature and development of significant thermal gradients in steel sections exposed to fire. In turn, the rise in steel temperature causes a severe reduction in the load carrying capacity of steel members, and development of additional internal forces if the member is restrained. 
2. A new approach is developed based on basic heat transfer principles for computing the influence of partial loss of fire protection on the temperature profile in steel sections exposed to fire.

3. Results from the analysis show that $5 \%$ loss of insulation can reduce fire resistance of a steel column from $3 \mathrm{~h}$ to $90 \mathrm{~min}$.

4. There is a lack of data on the heat transfer parameters (convection and radiation) in the region where fire protection is damaged or lost in a protected steel section.

5. The simplicity and versatility of the proposed approach makes it attractive for application in fire resistance assessment in design and analysis situations.

\section{Acknowledgements}

The research presented in this paper is supported by the National Science Foundation (Grant No. 0652292) and Department of Commerce/National Institute of Standards and Technology (Grant No. 60NANB7D6120). Any opinions, findings, and conclusions or recommendations expressed in this paper are those of the authors and do not necessarily reflect the views of the sponsors.

\section{References}

1. Tomecek DV, Milke JA (1993) A study of the effect of partial loss of protection on the fire resistance of steel columns. Fire Technol 29(1):4-21

2. Ryder NL, Wolin SD, Milke JA (2002) An investigation of the reduction in fire resistance of steel columns caused by loss of spray-applied fire protection. J Fire Prot Eng 12(1):31-44

3. Fontana M, Knobloch M (2004) Fire resistance of steel columns with partial loss of fire protection. In Proceedings of the IABSE symposium Shanghai 2004 metropolitan habitats and infrastructure. IABSE report, vol 88. Shanghai, China, ISBN 3-85748-110-2

4. Milke JA, Ryder N, Wolin S (2003) Analyses of the impact of loss of spray-applied fire protection on the fire resistance of steel columns. In: Fire safety science-proceedings of the seventh international symposium, pp 1025-1036

5. Pessiki S, Kwon K, Lee BJ (2006) Fire load behavior of steel building columns with damaged spray-applied fire resistive material. In: Fourth international workshop structures in fire. Aveiro, Portugal, pp 235-245

6. Kang Y, Hadjisophocleous GV, Khoo HA (2006) The effect of partial fire protection loss on the fire resistance reduction of steel beams. In: Proceeding of fourth international workshop structures in fire. Aveiro, Portugal, pp 63-74

7. Purkiss JA (2007) Fire safety engineering design of structures, 2nd edn. ButterworthHeinemann, Linacre House, Jordan Hill, Oxford

8. Buchanan AH (2002) Structural design for fire safety. Wiley, Chichester

9. Staggs JEJ, Phylaktou HN (2008) The effects of emissivity on the performance of steel in furnace tests. Fire Saf J 43(1):1-10

10. EC3 (2005) EN 1993-1-2: design of steel structures. Part 1-2: general rules - structural fire design. European Committee for Standardization, Brussels

11. ANSYS (2007) ANSYS multiphysics, version 11.0 SP1. ANSYS Inc, Canonsburg 
12. Wang YC (2002) Steel and composite structures, behavior and design for fire safety. Spon Press, London

13. Both C, Twilt L (1990) Report no. BI-89-208. TNO Building and Construction Research, Netherlands

14. EC1 (2002) EN 1991-1-2: actions on structures. Part 1-2: General actions - actions on structures exposed to fire. European Committee for Standardization, Brussels

15. Isolatek International (2008) CAFCO 300 guide specifications. Stanhope http://www. cafco.com/pdfs/CAFCO $\% 20300 \% 20$ Brochure.pdf

16. Hot Disk AB (2007) Thermal constants analyzer-TPS $2500 \mathrm{~s}$. Chalmers University of Technology, Gothenburg. http://www.hotdiskinstruments.com/images/stories/pdf/ TPS2500.pdf

17. Log T, Gustafsson SE (1994) Transient plane source (TPS) technique for measuring thermal transport properties of building materials. Fire Mater 19(1):43-49

18. Bentz DP, Prasad KR (2007) Thermal performance of fire resistive materials I. Characterization with respect to thermal performance models. Report BFRL-NIST 7401. Gaithersburg

19. Dwaikat MMS, Kodur VKR, Quiel SE, Garlock MEM (2010) Experimental behaviour of steel beam-columns subjected to fire-induced thermal gradients. J Constr Steel Res (in press)

20. AISC (2005) Steel construction manual, 3rd edn. American Institute of Steel Construction, Chicago 